Revue d'histoire de l'Amérique française

REVUE D.HISTOIRE DE L'AMÉRIQUE FRANÇAISE

\title{
Pétain et de Gaulle dans la presse québécoise entre juin 1940 et novembre 1942
}

\section{Robert Arcand}

Volume 44, numéro 3, hiver 1991

URI : https://id.erudit.org/iderudit/304899ar

DOI : https://doi.org/10.7202/304899ar

Aller au sommaire du numéro

Éditeur(s)

Institut d'histoire de l'Amérique française

ISSN

0035-2357 (imprimé)

1492-1383 (numérique)

Découvrir la revue

Citer cet article

Arcand, R. (1991). Pétain et de Gaulle dans la presse québécoise entre juin 1940 et novembre 1942. Revue d'histoire de l'Amérique française, 44(3), 363-395. https://doi.org/10.7202/304899ar
Résumé de l'article

Cet article, qui s'appuie sur un corpus d'éditoriaux extrait de quatre quotidiens de tendance clérico-nationaliste ou libérale, démontre que, contrairement à une interprétation largement répandue, le Québec français n'était pas unanimement pétainiste durant la Seconde Guerre mondiale. L'étude met en lumière trois discours sur Pétain et de Gaulle entre juin 1940 et novembre 1942. Alors que Le Devoir affiche sans ambiguïté sa sympathie pour Pétain, L'Action catholique, porte-parole de l'Archevêché de Québec, refuse de prendre parti. De son côté, la presse libérale, représentée par Le Canada et Le Soleil, se montre de plus en plus hostile à Pétain et favorable au chef de la France libre. 


\title{
PÉTAIN ET DE GAULLE DANS LA PRESSE QUÉBÉCOISE ENTRE JUIN 1940 ET NOVEMBRE 1942
}

\author{
ROBERT ARCAND \\ Département d' histoire \\ Université de Montréal
}

\section{RÉSUMÉ}

Cet article, qui s'appuie sur un corpus d'éditoriaux extrait de quatre quotidiens de tendance clérico-nationaliste ou libérale, démontre que, contrairement à une interprétation largement répandue, le Québec français n'était pas unanimement pétainiste durant la Seconde Guerre mondiale. L'étude met en lumière trois discours sur Pétain et de Gaulle entre juin 1940 et novembre 1942. Alors que Le Devoir affiche sans ambiguïté sa sympathie pour Pétain, L'Action catholique, porte-parole de l'Archevêché de Québec, refuse de prendre parti. De son côté, la presse libérale, représentée par Le Canada et Le Soleil, se montre de plus en plus hostile à Pétain et favorable au chef de la France libre.

\section{ABSTRACT}

This article shows that, contrary to a popular interpretation, Quebec francophones did not unanimously support Pétain during the Second World war. Based on an analysis of editorials from four newspapers, with liberal or clerico-nationalist opinions, the study points to three different views on Pétain and de Gaulle, between June 1940 and November 1942. While Le Devoir reveals unambiguous sympathy for Pétain, L'Action catholique, mouthpiece of the Quebec archbishop, prefers not to take sides. As to the liberal press, represented by Le Canada and Le Soleil, it is increasingly hostile to Pétain and favorable to General de Gaulle's action for the liberation of France.

L'année 1990 marque le cinquantième anniversaire de la chute de la France, survenue en juin 1940, dont le caractère aussi soudain qu'imprévu bouleversa la population québécoise restée attachée à son ancienne mère patrie. C'est l'occasion de revenir sur ce mythe d'un Québec français essentiellement favorable au maréchal Pétain et indifférent, voire hostile, au combat mené par le général de Gaulle lors de la Seconde Guerre mondiale. Selon Pierre Savard:

Unanimes à réprouver Hitler autant que Staline, les Canadiens français restent plus sensibles à la France de Vichy qu'à celle, 
encore bien peu connue, de De Gaulle. La propagande de Vichy trouve un sol favorable dans la vallée du Saint-Laurent. (...) Jusqu'à la défaite finale et même au-delà, le «vieillard qui joue en maître la partie la plus difficile qu'ait à jouer actuellement un chef d'État» (Lionel Groulx) garde la sympathie des Canadiens français pour qui Vichy représente, vu de loin, le retour à la vraie France. $^{1}$

Bien que certains historiens, comme Paul Couture ${ }^{2}$ et Mason Wade $^{3}$, aient signalé l'existence d'un courant plus sympathique aux gaullistes, c'est toujours l'image d'un Québec pétainiste qui domine l'historiographie des rapports France-Québec. Même en 1990, Dale Thomson, dans son étude De Gaulle et le Québec, affirme que, si le Canada anglais penchait du coté de la France libre, « ...les Canadiens français, eux, se rangeaient davantage du côté de Pétain qui s'engageait à rétablir les vieilles valeurs françaises, le catholicisme notamment» ${ }^{4}$.

Selon nous, cette vision d'un Québec unanimement pétainiste s'explique en grande partie par les choix des historiens qui, jusqu'à récemment, ont privilégié le discours clérico-nationaliste et négligé la presse libérale considérée peu représentative de la pensée québécoise d'avant $1945^{5}$. Toutefois, dans les années 1970 et 1980, Yves Roby, R. R. Heintzman, Fernande Roy et d'autres spécialistes ont contesté cette démarche et mis en lumière l'existence d'un discours libéral, aucunement marginal, dans le Québec de la première moitié du $\mathrm{XX}^{\mathrm{e}}$ siècle $^{6}$. De leurs travaux ressort un paysage idéologique modifié et plus équilibré, dominé par deux grands courants: le libéralisme et le clérico-nationalisme.

Dans ce contexte, nous pouvons remettre en cause ce portrait d'un Québec français essentiellement pétainiste et indifférent à de Gaulle et

1 Pierre Savard, «Les Canadiens français et la France», Paul Painchaud, Le Canada et le Québec sur la scène internationale (Québec, Presses de l'Université du Québec, 1977), 492493.

2 Paul M. Couture, The Politics of Diplomacy: the Crisis of Canada-France Relations, 1940-1942. Thèse de Ph.D. (histoire), Université York, 1981, 395 p.

3 Mason Wade, Les Canadiens français de 1760 à nos jours. Tome 2: 1911-1963 (Ottawa, Le Cercle du livre français, 1963), 393.

4 Dale C. Thomson, De Gaulle et le Québec (Ville Saint- Laurent, Éditions du Trécarré, 1990), 38.

5 Fernande Roy a bien analysé ce parti pris historiographique, qui postule un monolithisme idéologique, dans Progrès, harmonie, liberté: le libéralisme des milieux d'affaires francophones de Montréal au tournant du siècle (Montréal, Boréal, 1988), 11-35.

6 F. Roy, op. cit.; Yves Roby, Les Québécois et les investissements américains (19181929) (Québec, Presses de l'Université Laval, 1976), 250 p.; R. R. Heintzman, The Struggle for Life: the French Daily Press of Montreal and the Problems of Economics Growth in the Age of Laurier, 1896-1911. Thèse de Ph.D. (histoire), Université York, 1977. 
nous croyons utile de réexaminer la question en accordant sa juste place à l'opinion libérale. Cet article analyse et compare les discours sur le maréchal Pétain et le général de Gaulle, tenus par quatre quotidiens influents et clairement identifiés, soit au libéralisme, soit au clérico-nationalisme. Du côté libéral, nous étudions $L e$ Canada ${ }^{7}$, quotidien montréalais considéré comme l'organe «officieux» du Parti libéral fédéral, et $L e$ Soleil ${ }^{8}$ de Québec, propriété du sénateur libéral Jacob Nicoll, mais qui jouit d'une plus grande latitude au niveau de la politique éditoriale. De son côté, la presse clérico-nationaliste est représentée par Le Devoir ${ }^{9}$ de Montréal, journal nationaliste de combat dont le discours durant la guerre se caractérise par son opposition à la participation du Canada aux hostilités, et par L'Action catholique ${ }^{10}$, identifié comme le porte-parole de l'Archevêché de Québec. Contrairement au Devoir, le quotidien catholique de Québec, influencé par la position du cardinal Villeneuve, appuie fermement l'effort de guerre canadien.

Ces quatre journaux ${ }^{11}$ partagent une même culture politique britannique et appuient tous la cause des Alliés. Par "presse libérale», nous entendons l'ensemble des journaux qui prônent les grandes valeurs libérales de démocratie, de liberté, de progrès. Bien qu'elle affirme souvent partager ces idéaux, la presse clérico-nationaliste propose surtout une autre hiérarchie des valeurs axée sur la primauté de concepts traditionnels, tels la famille, le ruralisme, le respect de l'ordre social et l'obéissance à l'Église catholique, définis comme les conditions essentielles à la survie du peuple canadien-français.

Contrairement à ce qu'a pu affirmer Pierre Elliot Trudeau ${ }^{12}$, le courant clérico-nationaliste n'est aucunement monolithique. Il se divise en plusieurs tendances, dont deux principales: l'une mettant davantage l'accent sur la religion, représentée par L'Action catholique, et l'autre, surtout nationaliste, illustrée par Le Devoir. Cette diversité

7 Sur la presse libérale au Québec, voir Claude Couture, La presse libérale au Québec entre 1929 et 1935. Thèse de Ph.D. (histoire), Université de Montréal, 1987, 428 p. Sur Le Canada, voir Jean-Guy Genest, "Le Canada, 1920-1921», Idéologies au Canada français, 1900-1929 (Québec, Presses de l'Université Laval, 1974), 29-43.

8 Sur Le Soleil, voir Yvan Roy, «Le Soleil», Idéologies au Canada français, 1940-1976 (Québec, Presses de l'Université Laval, 1981), 161-178.

9 Sur Le Devoir, voir Pierre-Philippe Gingras, Le Devoir (Montréal, Libre Expression, 1985), 295 p. et André-J. Bélanger, op. cit, 27-158.

10 Sur L'Action catholique, voir Richard Jones, L'Idéologie de L'Action catholique (1917-1939) (Québec, Presses de l'Université Laval, 1974), 359 p.

11 Le tirage de ces quotidiens en 1940 est le suivant: L'Action catholique: 59 641; Le Canada: 15 242; Le Devoir: 20 212; et Le Soleil: 59686. 10-37.

12 Pierre Elliot Trudeau, La grève de l'amiante (Montréal, Éditions du jour, 1970), 
nous oblige souvent à traiter ces journaux comme deux entités distinctes, bien que faisant partie d'une même famille idéologique. En contre-partie, la presse libérale peut davantage être traitée comme un tout puisque Le Canada et Le Soleil, malgré certaines différences liées surtout à la nature de leurs liens avec le Parti libéral, présentent une opinion plus homogène lorsqu'ils s'expriment sur les événements en provenance de France ${ }^{13}$.

Nous avons procédé de la manière suivante. D'abord, nous avons constitué un corpus composé de l'ensemble des éditoriaux portant sur la France ${ }^{14}$, publiés par les quatre journaux entre le 16 juin 1940, date de l'arrivée au pouvoir du maréchal Pétain, et le 10 novembre 1942, moment de la rupture des relations diplomatiques entre le Canada et le régime de Vichy. Nous avons ensuite lu les textes attentivement et à chaque apparition des mots «Pétain» et «de Gaulle», le commentaire de l'éditorialiste a été relevé et reporté sur une fiche où, pour chaque quotidien, les opinions sont classées comme favorables ou défavorables au personnage ${ }^{15}$. Finalement, nous avons procédé à la normalisation des énoncés en les regroupant sous un certain nombre de thèmes généraux ${ }^{16}$. Les résultats sont présentés sous forme de tableaux illustrant, de façon quantitative, les idées-forces du discours de chacun des journaux sur ces deux personnalités françaises. Chaque tableau est complété par une annexe qui illustre la répartition des mentions dans le temps. Les trois sous-périodes correspondent au degré d'implication de Vichy dans la collaboration avec l'Allemagne ${ }^{17}$.

Cette méthode a cependant le désavantage de trop compartimenter des opinions souvent beaucoup plus nuancées que le laisse voir notre classification. De plus, surtout dans le cas de la presse clérico-nationaliste, un certain nombre d'événements importants impliquant Pétain

13 Il ne faudrait pas pour autant en conclure que le libéralisme québécois présente un aspect uniforme. Si les deux quotidiens que nous avons choisis s'inscrivent dans un courant «libéral conservateur», nous sommes conscient de l'existence d'autres tendances, dont celle plus radicale représentée par Le Jour de Jean-Charles Harvey. Victor Téboul, Le Jour, émergence du libéralisme moderne au Québec (Montréal, Hurtubise HMH, 1984), $436 \mathrm{p}$.

14 Nombre d'éditoriaux retenus, L'Action catholique: 41; Le Canada: 81; Le Devoir: 29 : Le Soleil: 78.

15 Par exemple, l'expression «Pétain collabore avec l'Allemagne» est classée défavorable, alors qu'une autre affirmant que «De Gaulle résiste aux nazis» est jugée favorable, puisque tous les journaux appuient la cause alliée. Au moindre doute sur le sens d'un commentaire, celui-ci est classé comme «neutre».

16 Ainsi, les trois commentaires défavorables suivants: «Pétain travaille pour les Allemands», «Le chef de l'État français accepte de livrer la main-d'œuvre française au Reich» et «Le vieux maréchal s'oriente vers la collaboration avec les nazis» sont regroupés sous le thème plus général, «Pétain collabore avec l'Allemagne».

17 Voir les tableaux 1 à 8 à la suite de l'article. 
ou de Gaulle ne suscitent aucun éditorial, les journaux préférant livrer leurs opinions ailleurs dans leurs pages. Pour combler quelque peu ces lacunes, une analyse qualitative plus détaillée du contenu des éditoriaux complète la présentation des tableaux. Également, lors d'événements importants, nous utilisons, d'une façon essentiellement qualitative, quelques extraits révélateurs du bloc-notes que l'on retrouve en première page du quotidien Le Devoir, et de la chronique «En marge de la guerre» où L'Action catholique livre parfois d'intéressants commentaires sur la situation en France.

\section{1 - RAPPEL HISTORIQUE}

Le 16 juin 1940, le maréchal Pétain ${ }^{18}$, âgé de 84 ans et auréolé d'un grand prestige pour son rôle dans la guerre de 1914-1918, est appelé à la direction d'une France déjà écrasée par les forces allemandes. Hostile dès le départ à l'idée d'une nouvelle guerre, il accepte un très dur armistice qui, en plus de laisser le territoire français occupé aux deux-tiers, place la France entièrement dans l'orbite de l'Allemagne. Pour le maréchal, les causes de la défaite française sont d'abord morales. Il se donne donc pour mission de restaurer sa patrie, grâce à un programme appelé Révolution nationale, où, en favorisant un retour aux valeurs traditionnelles, il souhaite faire de la France un État corporatiste et autoritaire.

Décidé à s'en tenir strictement aux termes de l'armistice, Pétain doit pourtant se résoudre à collaborer avec l'Allemagne, tant la France est alors sous la dépendance du vainqueur. C'est dans le but de fixer les termes de cette collaboration qu'il accepte de rencontrer Hitler à Montoire, le 24 octobre 1940, et que sont négociés les Protocoles de Paris, en mai $1941^{19}$. Durant la période, le chef de l'État français partage d'abord le pouvoir avec Pierre Laval, renvoyé en décembre 1940 à cause d'un désaccord sur la façon de mener la collaboration, puis avec l'amiral Darlan qui tente également de conclure une entente avec l'Allemagne. Toutefois, en avril 1942, Pétain se voit forcé de reprendre Laval comme premier ministre, ce qui signifie l'entrée de plain-pied de Vichy dans la voie de la collaboration avec le Reich.

Le 18 juin 1940, au moment même ou Pétain demande l'armistice, le général Charles de Gaulle ${ }^{20}$, ancien sous-secrétaire d'État à la guerre, lance un appel sur les ondes de la British Broadcasting Corporation $(\mathrm{BBC})$ où il demande aux Français de refuser la capitulation et

18 Sur Pétain, voir Marc Ferro, Pétain (Paris, Fayard, 1987), 789 p.

19 Sur ces deux épisodes, voir ibid., 184-197 et 310-324.

20 Sur de Gaulle, voir Jean Lacouture, De Gaulle. Tome 1: Le rebelle (Paris, Seuil, 1984), $870 \mathrm{p}$. 
de poursuivre la lutte contre l'Allemagne. Peu connu et disposant de faibles moyens, de Gaulle doit lutter ferme pour établir sa crédibilité auprès des Français et des Alliés. N'ayant d'abord droit qu'au titre de «chef des Français libres», accordé par Churchill, il est également l'objet de la méfiance des États-Unis qui préfèrent miser sur leur influence à Vichy. Toutefois, son prestige s'accroît rapidement, principalement lorsque l'ensemble de l'Afrique équatoriale française (AEF) se rallie à sa cause, à la fin d'août 1940. De Gaulle s'efforce également d'accroître sa crédibilité en nommant des représentants auprès des gouvernements alliés, et en assurant la présence de ses troupes sur nombre de théâtres d'opérations, dont la Syrie, à l'été 1941. Aussi, malgré son échec à Dakar en octobre 1940, il parvient à s'imposer comme interlocuteur auprès des Alliés, bien que ceux-ci refusent à son mouvement le titre de gouvernement français en exil.

\section{2 - LA PRESSE QUÉBÉCOISE ET LE MARÉCHAL PÉTAIN}

Comment la presse québécoise juge-t-elle l'action du maréchal Pétain à une époque où, compte tenu de l'ambiguïté des politiques de Vichy ${ }^{21}$, il est souvent facile d'interpréter les mêmes événements d'une façon contradictoire, en fonction de la sympathie ou de l'antipathie qu'inspire le personnage? De prime abord, la personnalité du maréchal Pétain, vainqueur de Verdun et catholique convaincu, semble de nature à plaire aussi bien aux libéraux qu'aux cléricaux-nationalistes. Toutefois, les circonstances dans lesquelles il est appelé à gouverner, la nature de son programme politique, l'action de ses collaborateurs et même la situation politique canadienne, sont autant de facteurs susceptibles de soulever d'importantes divergences au sein de l'opinion publique québécoise.

Comme l'indiquent les tableaux 1 à 4 , ce sont les organes clériconationalistes qui montrent le plus de sympathie pour le maréchal Pétain. Nous retrouvons d'abord Le Devoir ${ }^{22}$ (tableau 1: 90,7\% favorables, $5,8 \%$ défavorables et 3,5\% neutres) qui développe, surtout dans les premiers mois suivant l'armistice, un discours très favorable où il insiste sur l'idée que le maréchal, chef d'État dont l'intégrité ne

21 Sur les politiques de Vichy, voir Robert Paxton, La France de Vichy, 1940-1944 (Paris, Seuil, 1973), 375 p.

22 Le Devoir traite moins de Pétain et du général de Gaulle en éditorial que les autres journaux. Il ne faut pas voir là un signe d'indifférence pour la situation de la France et, d'une façon plus générale, pour la vie internationale, une politique de repli sur soi, propre à la presse clérico-nationaliste, selon certains. Il s'agit essentiellement d'un choix rédactionnel, le journal préférant souvent traiter de la France dans son bloc-notes. Après vérification, nous pouvons affirmer que les opinions exprimées dans le bloc-notes s'accordent avec celles révélées par l'analyse de contenu des éditoriaux. 
fait pas de doute (8 mentions), se serait sacrifié pour sauver sa patrie au moment de la défaite de juin 1940 (5 mentions). Selon Georges Pelletier ${ }^{23}$ : «La vérité, c'est qu'il n'y a peut- être pas dans l'histoire de France ces années-çi, figure plus noble que celle du maréchal Pétain (...) Pétain a préservé son pays en 1940 au prix même de sa réputation d'invincible soldat. ${ }^{24}$

Cette sympathie du quotidien nationaliste de Montréal est motivée par son appui inconditionnel aux réformes mises de l'avant par Pétain dans le but de restaurer la France (11 mentions). Le journal, idéalisant fortement la Révolution nationale, se donne pour but d'expliquer et de défendre le programme du chef de l'État français. En août 1940, Georges Pelletier réfute les accusations de fascisme lancées contre le régime de Vichy, en mettant l'accent sur les principes qui guident l'action de son chef:

Gouvernement fasciste celui du maréchal Pétain (...) parce qu'il met au-dessus des droits de l'individu les droits primordiaux de la famille, du travail, de la patrie? Qu'il entend réformer les mœurs tant privées que publiques, réclamer le droit à la vie pour l'enfant, le droit à sa religion pour l'adulte, le droit d'association pour les religieux comme pour les laïcs, faire cesser la propagande, les menées, les pratiques anticléricales? ${ }^{25}$

Cet appui à la Révolution nationale amène le journal à accorder le bénéfice du doute à Pétain lorsqu'il est question de la collaboration franco-allemande. Ne pouvant croire qu'un chef d'État qui prône des politiques aussi saines puisse, en même temps, se compromettre avec le nazisme, il fait table rase des «rumeurs» de collaboration avec l'Allemagne. Le journal développe plutôt l'idée que le maréchal résiste avec acharnement aux pressions nazies (15 mentions), en s'en tenant scrupuleusement aux termes de l'armistice (4 mentions). Au printemps 1942, alors que la réalité de la collaboration devient difficile à nier, Georges Pelletier compare l'attitude du chef de l'État français devant Hitler à celle d'autres dirigeants européens: «Celui-ci a cassé Hodza, brutalisé Schusschnig, intimidé un temps Staline, il domine Mussolini. Pétain n'a pas encore cédé ce que Hitler recherche (...) ${ }^{26}$ En fait, les organes clérico-nationalistes s'en tiennent souvent

23 Georges Pelletier (1880-1947), avocat de profession, succède à Henri Bourassa à la direction du quotidien Le Devoir en 1932 et s'y maintient jusqu'à sa mort. Durant la guerre, il se signale par son opposition à la participation du Canada aux hostilités et par son zèle anticonscriptionniste.

24 Le Devoir, «Les régimes passent, la France demeure», 29 juin 1940.

25 Le Devoir, «Le régime du maréchal Pétain», 3 août 1940.

26 Le Devoir, «La guerre, la paix et la France», 7 mars 1942. 
à une image idéalisée de Pétain, celle du restaurateur de la France, et n'accordent pas beaucoup d'importance aux détails de ses politiques en dehors de son projet de société.

Dans ce contexte, Le Devoir comprend mal l'acharnement mis par la presse libérale, par les gaullistes et par les milieux anglophones à dénoncer le maréchal Pétain. Défenseur farouche de celui-ci, il engage régulièrement la polémique avec ses détracteurs, qu'il qualifie de gens de mauvaise foi (10 mentions). En décembre 1941, Georges Pelletier admet la présence d'individus louches dans le gouvernement français, mais il s'en prend à ceux qui condamnent systématiquement le maréchal:

(...) on a mauvaise grâce aujourd'hui, soit entre Français véritables, soit dans les milieux de langue française à l'étranger, de ridiculiser, de honnir, de vilipender le chef de l'État français, comme le font ici de façon systématique, de rares aventuriers de plume, Français véritables ou Canadiens déconsidérés, classés au rang des calomniateurs de carrière les plus bas, et dont les insultes jaillissent de la crotte à même laquelle ils se complaisent à modeler leurs idoles. ${ }^{27}$

Le journal souligne que Pétain est le chef légitime de la France (3 mentions) et qu'il jouit de la pleine confiance du peuple français (7 mentions). Contre ceux qui croient qu'il n'est qu'un fantoche et un vieillard sénile, Le Devoir soutient que le maréchal est réellement le maître à Vichy et qu'il assume ses décisions en toute lucidité (3 mentions). Toujours en décembre 1941, Georges Pelletier, se référant à un article du Herald Tribune de New York, insiste sur l'idée qu' «(...) il n'y a partout en France que respect pour le maréchal Pétain. Il est indubitablement le chef de la France d'aujourd'hui» ${ }^{28}$. Plus loin, soulignant la bonne santé physique et mentale du maréchal, il ajoute que «(...) Pétain prend pour son cabinet les décisions graves et (...) il assume devant l'histoire toute la responsabilité de ses actes politiques» ${ }^{29}$.

Finalement, Le Devoir, plutôt loquace durant les premiers mois suivant l'armistice, se fait plus discret sur les politiques du maréchal Pétain lorsqu'il devient clair que son régime collabore avec l'Allemagne. Pour contourner l'impasse, le journal cesse de produire des éditoriaux sur Vichy après le retour de Laval, en avril 1942, et relègue dans son bloc-notes les quelques commentaires qu'il se hasarde encore

27 Le Devoir, «La France ne trahit personne», 20 décembre 1941.

28 Loc. cit.

29 Loc. cit. 
à livrer sur ce gouvernement. Toutefois, comme l'illustre cet extrait datant de juin 1942, le journal continue de faire confiance au maréchal dans sa volonté de résister aux nazis: «Ce qui est certain, quoi qu'on ait dit cent fois depuis juin 1940, c'est que le gouvernement de Vichy (...) n'a jamais livré sa flotte de guerre aux Allemands et que Pétain s'est obstiné à observer les termes stricts de l'armistice.» ${ }^{30}$

L'Action catholique (tableau 2: 68,9\% favorables; $27,1 \%$ défavorables; et $4 \%$ neutres), tout en se montrant très sympathique au maréchal Pétain, exprime davantage de réserves. À l'exemple du Devoir, le quotidien catholique de Québec affirme fréquemment, surtout durant les premiers mois après l'armistice, son soutien inconditionnel aux réformes mises de l'avant par le chef du gouvernement de Vichy. Catholique fervent (5 mentions), celui-ci tâche de restaurer sa patrie vaincue en lui redonnant son visage chrétien (37 mentions). Louis-Philippe Roy ${ }^{31}$ exprime sa satisfaction:

(...) nous ne cesserons d'applaudir le vieux maréchal dans sa lutte contre les sociétés secrètes, contre l'alcoolisme, contre les criminels expulsés des autres pays, contre l'immoralité du film, contre les trusts, pas plus que nous ne cesserons d'applaudir le courageux chef dans sa lutte pour la restauration de la famille, du travail, de la natalité, pour la reconnaissance civile des religieux et religieuses. ${ }^{32}$

C'est pourquoi le journal, idéalisant lui aussi fortement la Révolution nationale, défend Pétain contre ses détracteurs (13 mentions), soulignant qu'il est bien différent de Hitler et de Laval (3 mentions), qu'il gouverne bien la France et agit dans le sens des intérêts de sa patrie (10 mentions). Comme Le Devoir, le quotidien catholique de Québec accorde le bénéfice du doute au chef de l'État français à propos de la collaboration avec l'Allemagne et affirme qu'il résiste fermement à ses pressions (11 mentions). Néanmoins, le journal doit parfois admettre que le maréchal collabore avec le Reich ( 2 mentions) et qu'il pratique des politiques plutôt discutables ( 2 mentions), comme la persécution des Juifs. Toutefois, il montre une très grande indulgence chaque fois qu'il se hasarde à critiquer le maréchal et demande à ses lecteurs de lui faire confiance et de le respecter, même s'ils ne sont pas toujours d'accord avec les politiques de Vichy (9 mentions). L'Action catholique croit que Pétain n'est pas vraiment libre

30 Le Devoir, «Affaires de France», 17 juin 1942, 1.

31 Louis- Philippe Roy (1900-1966), médecin devenu journaliste, se signale par son zèle anticommuniste et par son soutien au général Franco lors de la guerre d'Espagne. Membre de l'équipe de L'Action catholique depuis 1930, il en devient le rédacteur en chef en 1945.

32 L'Action catholique, «Ne faisons pas le jeu des ennemis», 21 novembre 1940. 
(4 mentions) et qu'il se comporterait autrement s'il pouvait agir à sa guise (3 mentions). Sa faible capacité de résistance aux pressions nazies ( 3 mentions) est attribuée à son grand âge. Louis-Philippe Roy retient cette explication au moment de Montoire:

Pourquoi Pétain a-t-il cédé? La réponse est bien simple. On ne peut exiger d'un vieillard de 84 ans qu'il prolonge durant plusieurs mois un effort surhumain (...) Grignoté à l'intérieur par les ambitions effrénées de Pierre Laval et pressé de l'extérieur par un vainqueur plus coquin qu'astucieux, le maréchal n'a pu résister. ${ }^{33}$

S'il affirme lui aussi que le maréchal Pétain s'est sacrifié pour sauver la France en juin 1940 (8 mentions), le quotidien catholique de Québec croit néanmoins que le maréchal s'est trompé en acceptant l'armistice (15 mentions) et qu'il aurait dû poursuivre la lutte dans l'empire français. Mais il n'a pas pour autant trahi sa patrie en capitulant mais a agi dans ce qu'il croyait être alors l'intérêt de la France (9 mentions), comme l'explique Eugène L'Heureux ${ }^{34}$ :

(...) cette erreur probable de l'armistice ne mérite aucunement d'être classée parmi les actes abominables que l'on appelle trahison. Avant de condamner comme une trahison le geste accompli par les chefs de la France le 17 juin 1940, il faut se représenter la situation cahotique de ce pays après l'invasion à vive allure de son sol par les armées allemandes. ${ }^{35}$

Pour se démarquer de certains nationalistes qui ne jurent que par Pétain, L'Action catholique juge bon de préciser que celui-ci n'est pas infaillible et qu'il peut commettre des erreurs, même s'il est catholique (6 mentions). Ainsi, lui reproche-t-on de faire trop confiance à Laval (7 mentions) qui, avec les nazis ( 2 mentions), complote contre lui et travaille à miner son prestige. Louis-Philippe Roy est donc soulagé lorsque Pétain renvoie son premier ministre en décembre 1940 (7 mentions) et croit que maintenant:

Débarrassé d'un politicien roué et démesurément ambitieux (...) le gouvernement de Vichy poursuivra son œuvre de restauration de la France. Hitler voudrait bien obtenir des gouvernants français une collaboration plus étroite, mais le fier militaire n'est pas homme à transiger avec l'honneur (....). ${ }^{36}$

33 L'Action catholique, «La France est trahie», 29 octobre 1940.

34 Eugène L'Heureux, journaliste catholique, s'illustre dans les années 1930 par son combat contre les abus du capitalisme. Rédacteur en chef de L'Action catholique de 1939 à 1944 , il passe ensuite à la presse libérale où il collabore aux quotidiens Le Soleil et La Presse.

35 L'Action catholique, «À propos de Vichy», 19 août 1942.

36 L'Action catholique, «Encore la France», 17 décembre 1940. 
Le quotidien catholique de Québec s'intéresse grandement à la querelle entre partisans de Pétain et du général de Gaulle, qui divise les Français et même les Canadiens français. Fidèle reflet des positions de l'archevêché de Québec ${ }^{37}$, il choisit de rester neutre dans l'imbroglio français et tente de concilier les deux groupes. Le journal soutient qu'il n'est pas nécessaire de renier de Gaulle pour admirer Pétain et que les Canadiens français peuvent appuyer ces deux grands Français sans se contredire (11 mentions), car les deux hommes servent héroïquement leur pays (11 mentions). L'Action catholique développpe l'idée d'une double résistance: l'une de l'intérieur incarnée par Pétain et l'autre dirigée de l'extérieur par de Gaulle. Selon Eugène L'Heureux:

Si anormal que cela puisse apparaître, Pétain et de Gaulle sont des serviteurs héroïques de leur patrie. Chacun à sa manière et selon ses vues (...) ils servent la France et, avec ce pays d'apostolat, tout l'univers. Par des sentiers différents, ils gravissent le même Calvaire de la Rédemption des peuples assoiffés de légitime liberté..$^{38}$

Dans ce contexte, les éditorialistes enjoignent aux Canadiens français de ne pas s'entre-déchirer en s'impliquant dans une querelle qui ne regarde que les Français. Ils critiquent les partisans de Pétain qui s'attaquent à de Gaulle (8 mentions) et les gaullistes qui s'en prennent au chef de l'État français. En avril 1941, Eugène L'Heureux dit comprendre les désaccords entre les partisans européens des deux chefs. Toutefois :«(...) ce qui serait moins explicable et pour le Canada extrêmement désastreux, ce serait que nos compatriotes, habitant une région soustraite à ce dérangement inouï, offrent le scandale d'une chicane passionnée autour de Pétain et de Gaulle.» ${ }^{39}$

Très abondantes aux lendemains de l'armistice, alors que les éditorialistes sont enthousiasmés par la Révolution nationale, les mentions du nom de Pétain deviennent plus rares à partir du printemps 1941, quand s'intensifie la collaboration entre Vichy et le Reich. Dorénavant, plus discrète et plus nuancée, L'Action catholique demeure malgré tout très sympathique au maréchal. En août 1942, on peut encore lire dans ce journal: «(...) Nous aurions grandement tort de nous montrer hostile à Pétain et aux meilleurs de ses compagnons. Sur ce point (...) les esprits absolus doivent se tenir en garde contre leur tendance à verser dans les excès. ${ }^{40}$

37 Sur les positions de l'Église, voir Paul M. Couture, «Vichy-Free France Propaganda in Quebec, 1940 to 1942», Communications historiques (1978): 204-205.

38 L'Action catholique, «Impression d'un évêque-aumônier», 21 février 1941.

39 L'Action catholique, «Encore à propos de la France», 25 avril 1941.

40 L'Action catholique, «À propos de Vichy», 19 août 1942. 
La presse libérale présente un portrait moins flatteur des politiques de Pétain, mais sa critique est généralement modérée. Aux lendemains de l'armistice, Le Canada (tableau 3: 40,5\% favorables, $45,7 \%$ défavorables et 13,8\% neutres) et Le Soleil (tableau 4: 37,9\% favorables, $55,2 \%$ défavorables et $6,9 \%$ neutres), se portent à la défense d'une France vaincue et sévèrement prise à partie par le Canada anglais. Ces quotidiens montrent alors une réelle sympathie à l'endroit de Pétain qu'ils considèrent comme le chef légitime de la France (Le Soleil: 3 mentions). Ils affirment que Pétain se devait de capituler en juin 1940 (Le Canada: 3 mentions) et jugent positive son influence au moment de l'armistice (Le Soleil: 4 mentions). Bon catholique (Le Soleil: 3 mentions) et bien appuyé par le général Weygand (Le Soleil: 6 mentions), le maréchal gouverne bien la France et agit dans le sens de l'intérêt de sa patrie (Le Canada: 10 mentions, Le Soleil: 7), se préoccupant surtout d'éviter le maximum de souffrances aux Français (Le Soleil: 7 mentions). Les éditorialistes croient même qu'il reste l'ami de l'Angleterre (Le Canada: 3 mentions), malgré Mers El Kébir $^{41}$, et, surtout, soutiennent qu'il jouit d'une réelle autonomie à l'égard des Allemands ou de Laval (Le Canada: 6 mentions, Le Soleil: 5). En juillet 1940, le quotidien libéral de Montréal est heureux de citer le témoignage de William C. Bullit, ambassadeur des États-Unis en France, qui s'élève: «(...) contre l'opinion déjà répandue en Amérique et dans les pays britanniques que la France est devenue un État fasciste, que le maréchal Pétain n'est qu'un fantoche et que le maître véritable du pays est $M$. Pierre Laval et non le maréchal Pétain. ${ }^{42}$

Les quotidiens libéraux considèrent alors Pétain comme un homme honnête, dont l'intégrité ne fait pas de doute (Le Canada: 6 mentions, Le Soleil: 4). Ils lui accordent donc le bénéfice du doute lorsque s'élèvent les premières rumeurs de collaboration entre Vichy et le Reich, affirmant que le maréchal résiste à l'Allemagne et refuse de collaborer avec les nazis (Le Canada: 5 mentions, Le Soleil: 9). Tout en constatant le caractère douteux de certaines politiques de Vichy, comme les décrets de l'été 1940 sur le statut des Juifs, la presse libérale persiste à croire qu'on doit faire confiance à Pétain et le respecter même si l'on n'est pas toujours d'accord avec les politiques de son gouvernement (Le Canada: 2 mentions, Le Soleil: 13). En contradiction avec les propos cités plus haut, ces journaux avancent

41 Les 2 et 3 juillet 1940, la marine britannique, pour s'assurer que la flotte française ne tombe pas entre les mains des Allemands, ouvre le feu sur une escadre française mouillée à Mers El Kébir et coule plusieurs navires. Cette opération, qui fit 1297 victimes du côté français, contribua à rendre difficiles les rapports entre Vichy et la Grande-Bretagne durant le reste du conflit.

42 Le Canada, «Un témoignage», 22 juillet 1940. 
que le maréchal n'agirait pas comme il le fait s'il était vraiment libre (Le Canada: 3 mentions, Le Soleil: 5). En septembre 1940, le quotidien libéral de Québec condamne la politique antisémite, mais continue d'affirmer que: «(...) le maréchal Pétain est l'une des plus nobles et des plus belles figures de la France contemporaine. Au héros de Verdun, il est impossible de tenir rigueur de quoi que ce soit. Et puis pour condamner une seule de ses décisions, il faudrait d'abord connaître ses raisons.» ${ }^{43}$ Plus loin, il ajoute: «(...) nous avons dans cette loi, une preuve de plus que le gouvernement du très respectable et du très catholique maréchal Pétain n'est pas libre. Car s'il était libre, il n'aurait pas pu, c'est évident, promulguer une loi comme celle-là.» ${ }^{44}$

La presse libérale attribue plutôt la responsabilité de ces politiques néfastes à Pierre Laval et, si elle exonère le maréchal de tout blâme, lui reproche tout de même de mal s'entourer (Le Soleil: 4 mentions). Les journaux, surtout Le Canada, soulignent fréquemment l'opposition de Pétain aux politiques de son premier ministre ( 7 mentions) et, en décembre 1940, montrent beaucoup de satisfaction lorqu'il décide de le renvoyer (Le Canada: 7 mentions; Le Soleil: 3).

Cette bienveillance à l'égard du maréchal Pétain ne dure toutefois qu'un temps. En effet, on constate que, plus la politique de collaboration entre Vichy et l'Allemagne se précise, plus la presse libérale durcit le ton envers le chef de l'État français. Alors que les quotidiens clérico-nationalistes jugent ce dernier en fonction de son projet de société, les journaux libéraux fondent d'abord leur opinion sur son attitude en politique extérieure, principalement sur ses relations avec l'Allemagne et les Alliés. Dès après Montoire, le 24 octobre 1940, la presse libérale commence à s'inquiéter. Le Soleil entreprend même, par la plume de Willie Chevalier ${ }^{45}$, une campagne de dénonciation du régime de Vichy. Toutefois, les propos à l'endroit du maréchal restent modérés, les éditorialistes établissant une distinction entre celui-ci et les autres dirigeants de Vichy. Selon Willie Chevalier: «Dans l'entourage du vénérable $M$. Pétain, il y a aussi bien de sombres crapules, imposées au maréchal par les Allemands ou sur le caractère de qui il se trompe. Le héros de Verdun n'en reste pas moins digne de respect. $\gg^{46}$

Le point de rupture se situe au printemps 1941, alors que Vichy négocie les Protocoles de Paris avec les nazis et menace de rompre,

43 Le Soleil, «En marge d'une loi de Vichy», 13 septembre 1940.

44 Loc. cit.

45 Willie Chevalier, journaliste libéral, disciple d'Olivar Asselin, se signale par la campagne anti-Vichy et pro-de Gaulle qu'il signe dans Le Soleil, entre novembre 1940 et juillet 1941, sous le pseudonyme de "Vauquelin».

46 Le Soleil, «Nous sommes Français d'origine», 8 février 1941. 
à l'aide de sa marine de guerre, le blocus des côtes françaises établi par la Grande- Bretagne. A partir de ce moment, les deux quotidiens deviennent subitement plus sévères à l'endroit de Pétain, qu'ils dépeignent comme un partisan de la collaboration avec l'Allemagne (Le Canada: 6 mentions; Le Soleil: 11), qui pratique une politique hostile à l'Angleterre (Le Canada: 3 mentions; Le Soleil: 4) et travaille contre l'intérêt de sa patrie (Le Canada: 4 mentions; Le Soleil: 7). Mobilisée pour vendre la guerre et la cause alliée aux Canadiens français, la presse libérale s'expose à la contradiction si elle continue de se montrer sympathique à Pétain, alors qu'il est de plus en plus clair que son gouvernement collabore avec l'Allemagne.

Si le ton se durcit, Le Canada évite cependant les critiques trop sévères et semble encore croire que le maréchal peut se ressaisir. En novembre 1941, alors que les dirigeants français annulent une rencontre où devaient être fixées les conditions de la collaboration, le journal réagit à ce qu'il perçoit comme une tentative de résistance:

Nous devons nous contenter de souhaiter que le maréchal Pétain et ses collègues puissent poursuivre leur travail de reconstruction nationale, sans se voir obligés de céder d'un pouce aux ordres du vainqueur. (...) Les mois douloureux que nous traversons nous invitent au recueillement plus qu'aux attaques véhémentes, ils ne doivent pas nous interdire de garder au fond de nos cœurs l'espoir de radieux lendemains. ${ }^{47}$

Cette attitude conciliante semble s'expliquer par la controverse qui sévit alors au sujet du maintien des relations diplomatiques entre Ottawa et Vichy ${ }^{48}$. Dans ce contexte, une critique trop acerbe contre le chef d'un État reconnu par le Canada serait mal venue et maladroite de la part d'un journal aussi près du Parti libéral au pouvoir, puisqu'elle ne ferait que donner des arguments aux Conservateurs qui réclament la rupture avec la France.

Plus libre de ses mouvements et moins impliqué dans la défense des liens diplomatiques entre le Canada et Vichy, Le Soleil peut se montrer plus sévère à l'endroit de Pétain. Soulignant qu'une partie importante de la population française ne reconnaît plus l'autorité de son gouvernement (6 mentions), il reproche maintenant au maréchal d'avoir conclu l'armistice (14 mentions), de tromper les Alliés (4 mentions) et de pratiquer une politique qui fait souffrir les Français (4 mentions). Le quotidien libéral de Québec va parfois très loin dans la critique. Il présente le chef de l'État français comme un vieil entêté,

47 Le Canada, «L'entrevue qui n'a pas eu lieu», 28 novembre 1941.

48 Sur ce sujet, voir Paul M. Couture, article cité. 
mu par une peur exagérée du communisme (4 mentions), dont la carrière militaire est placée sous le signe du défaitisme (10 mentions). Le journal met également l'accent sur les sympathies du maréchal pour le fascisme et la dictature ( 9 mentions). En juin 1941, Willie Chevalier suggère même qu'il a pu trahir sa patrie au moment de l'armistice:

Il faut maintenant se rendre à l'évidence, se rappeler les sympathies de Pétain et de Weygand pour le fascisme. Pour tuer la République ses ennemis n'ont pas hésité à frapper leur patrie (...). $\mathrm{Du}$ jour où $\mathrm{H}$. Paul Reynaud les a appelés à la direction de l'armée, Pétain et Weygand, chaque fois qu'ils ont donné des ordres, ont fait reculer et retraiter les soldats. Au préalable, ils avaient évoqué la crainte du communisme - l'argument mis à la mode par Hitler - pour désarmer les régiments. Ils ont finalement imposé la capitulation. ${ }^{49}$

La presse libérale montre encore plus d'amertume lorsque Pétain rappelle Laval, en avril 1942, et développe plus que jamais l'idée que le maréchal est manipulé par ce politicien (Le Canada: 16 mentions). On y lit maintenant que le maréchal n'incarne plus la France (Le Soleil: 3 mentions) et qu'il n'a plus le droit de parler de l'honneur de son pays (Le Canada: 3 mentions). Toutefois, l'image la plus fréquente est celle d'un Pétain impuissant, prisonnier, sans autorité réelle (Le Canada: 21 mentions; Le Soleil: 19) et destiné à jouer en France le rôle tenu en Allemagne par le maréchal von Hindenburg, lors de l'avènement d'Hitler en 1933. Selon le quotidien libéral de Montréal:

Un fait demeure certain: Pétain ne compte plus dans le gouvernement français. Après la défaite, certains politiciens tarés ont voulu s'abriter sous son prestige et poursuivre à son ombre leurs petites combines maladroites. Le drapeau Pétain pend misérablement à la hampe. Le chef de l'État français devient un simple président sans pouvoir, une espèce de roi-soliveau. Nouvel Hindenburg, qui sait s'il ne verra pas surgir un Hitler français succédant à Laval. ${ }^{50}$

Promoteurs de l'effort de guerre du Canada auprès des Canadiens français, les journaux libéraux s'intéressent surtout à la politique extérieure du régime de Vichy et aux relations de notre pays avec ce gouvernement. Contrairement aux journaux clérico-nationalistes, ils commentent peu la Révolution nationale du maréchal Pétain et, le cas échéant, nous remarquons une divergence entre les deux quotidiens.

49 Le Soleil, «La fin d'un beau rêve», 11 juin 1941.

50 Le Canada, "Qui entourera le triste Laval», 18 avril 1942. 
Le Canada, plus indulgent, soutient que certaines réformes mises de l'avant par le maréchal sont excellentes (3 mentions) et va jusqu'à affirmer, lorsque Pétain crée un Conseil national français en janvier 1941, que le maréchal tente de donner une forme de représentation populaire à son régime $(3 \text { mentions })^{51}$. De son coté, Le Soleil ne montre aucune sympathie pour la Révolution nationale qu'il compare aux totalitarismes fasciste et nazi (5 mentions). En juillet 1941, Willie Chevalier livre le fond de sa pensée sur le programme du maréchal Pétain:

Nous refusons de croire au mythe d'une France purifiée et sanctifiée par les bons soins de herr Hitler et signor Mussolini. Nous croyons irréductiblement que toutes les réformes de M. Pétain ne sont qu'un leurre, parce que certaines s'inspirent des sales doctrines totalitaires, toutes ne s'appliquent qu'à une partie du pays et dans l'exacte proportion de la tolérance intéressée de l'envahisseur..$^{52}$

Finalement, Le Canada, plus impliqué politiquement, et conscient que l'opposition Pétain-de Gaulle a de graves répercussions au Canada français ( 2 mentions), dénonce l'attitude des nationalistes, qui exaltent la personne du maréchal Pétain, et l'associe souvent au fascisme (5 mentions). Après le plébiscite sur la conscription d'avril 1942, le porte-parole du Parti libéral semble prendre davantage conscience des risques que les nationalistes font courir à l'unité du pays. Ceci l'amène à insister davantage sur l'influence néfaste des idéologies de la droite française sur le moral de guerre des Canadiens français. Il croit cependant que le pétainisme est un mal qui touche surtout l'élite, alors que la masse serait plus portée à admirer les qualités incarnées par de Gaulle:

(...) il est certain que le culte morbide pour la «personne» du maréchal Pétain n'est pas chez nous un mal de l'âme populaire, mais un vice intellectuel, un snobisme des cercles où l'on pense. (...) Le vulgaire, c'est l'homme du peuple qui d'instinct admire le courage, la résistance, l'héroïsme et le sacrifice. Le mondain, c'est le monsieur correct qui respecte les intérêts, la tradition, l'«ordre» et les calculs «réalistes»... Il n'y a pas de terrain de rencontre entre les deux..$^{53}$

51 Le Canada, «Le Conseil national français», 28 janvier 1941.

52 Le Soleil, «La France et le 14 juillet», 12 juillet 1941.

53 Le Canada, «Vichy et nous», 22 mai 1942. 


\section{3 - LA PRESSE QUÉBÉCOISE ET LE GÉNÉRAL DE GAULLE}

L'appel lancé au peuple français par le général de Gaulle, le 18 juin 1940, passe presque inaperçu, aussi bien en France qu'au Québec. Seul Le Soleil signale ce discours, qu'il perçoit comme l'indice d'une division au sein de l'armée française sur l'opportunité d'accepter l'armistice ${ }^{54}$. Ce n'est qu'à partir d'août 1940, alors que de Gaulle s'adresse directement aux Canadiens français, que son nom commence à être mentionné par la presse québécoise.

Consciente que la chute de la France a de graves répercussions sur le moral de guerre des Canadiens français, la presse libérale montre immédiatement beaucoup d'enthousiasme pour le combat du général de Gaulle. Elle constate avec joie qu'une partie du peuple français refuse la capitulation et désire poursuivre la lutte contre l'Allemagne. Dès août 1940, Le Canada (tableau 5: 83,1\% favorables, 5,6\% défavorables et $11,3 \%$ neutres) et Le Soleil (tableau 6: 82,5\% favorables, $0 \%$ défavorables et $17,5 \%$ neutres) commencent à faire l'éloge du chef de la France libre. Ils insistent sur l'idée que l'homme du 18 juin poursuit la lutte aux côtés de l'Angleterre (Le Canada: 7 mentions; Le Soleil: 10) dans le but de libérer sa patrie (Le Canada: 8 mentions; Le Soleil: 7). Le quotidien libéral de Montréal s'explique:

Le général de Gaulle est le dernier lien qui unit la France à la Grande-Bretagne. (...) Il rallie autour de lui les Français qui n'acceptent pas la défaite et qui veulent revoir la France libre et grande. Grâce à lui, la France, aujourd'hui écrasée, pourra revendiquer sa part de la victoire pour laquelle nous combattons. ${ }^{55}$

Ces journaux vont donc accueillir très favorablement le ralliement aux gaullistes de la totalité de l'AEF, à la fin d'août 1940 (Le Soleil: 7 mentions): «L'idéal que le général de Gaulle préconise aux Français (...) est en train de rallier à la cause qu'il représente la plus grande partie de l'empire colonial de la France.» ${ }^{56}$ De même, à la fin de septembre 1940, ils approuvent la décision du chef de la France libre d'attaquer le port vichyssois de Dakar. Lors de cet événement, Le Canada insiste sur la tristesse du général de devoir se battre contre d'autres Français (8 mentions):

La situation du général de Gaulle est profondément douloureuse. Il a consacré sa vie à libérer son pays (...). Pour y parvenir, il doit croiser le fer avec des Français, avec des frères d'armes. Qui ne

54 Le Soleil, «Les récriminations tragiques», 19 juin 1940.

55 Le Canada, «France et Grande-Bretagne», 5 septembre 1940.

56 Le Soleil, «L'empire colonial de la France», 4 septembre 1940. 
comprend l'angoisse de ce patriote. Il tente, autant qu'il se peut, d'éviter les engagements qui rappelleraient le temps où les Français ne s'aimaient pas. ${ }^{57}$

La presse libérale évite d'abord d'opposer directement de Gaulle à Pétain et elle insiste parfois sur la complémentarité de l'action des deux hommes. Le Canada dit approuver les Canadiens français qui font confiance à la fois au maréchal et à de Gaulle ( 2 mentions), et $L e$ Soleil croit que Pétain, qui a déjà fait l'éloge de ce dernier, approuve secrètement son combat (5 mentions). Selon Willie Chevalier:

Les liens qui nous unissent à ce que l'on pourrait appeler la France juridique, celle du maréchal Pétain, ne sont pas incompatibles avec l'admiration qu'un Canadien français bien né et renseigné ne peut manquer d'éprouver pour le général Charles de Gaulle. (...) Soyons d'ailleurs certains que, malgré les apparences, Pétain approuve de Gaulle dans le fond de son cœur. ${ }^{58}$

Ce n'est que plus tard, principalement après l'affaire des Protocoles de Paris en mai 1941, que les organes libéraux commencent à opposer plus directement «l'héroïsme» du général de Gaulle à la «trahison» des dirigeants de Vichy (Le Soleil: 7 mentions) et à souligner que le chef de la France libre sert mieux l'honneur de sa patrie que Pétain (Le Canada: 4 mentions). Pour le quotidien libéral de Montréal: «De Gaulle parle, lui aussi, de l'honneur français. Mais il n'en parle pas d'une voix chevrotante, et ce n'est pas d'un honneur désséché, dévitalisé, froid et blanc comme la stèle d'une tombe. C'est d'un honneur jeune et frémissant que les civils comprennent.» ${ }^{59}$

Ayant pour mission de promouvoir la cause alliée au Québec, la presse libérale s'applique à justifier le combat du général de Gaulle, où il est peu connu et peu compris. Les journaux expliquent qu'il jouit de l'appui d'une forte majorité de Français (Le Canada: 4 mentions, Le Soleil: 7) et soulignent régulièrement ses qualités personnelles. Ils le présentent comme un patriote, à l'attitude pure et honorable, dont l'action sert les intérêts et la grandeur de sa patrie (Le Canada: 8 mentions, Le Soleil: 8). À la fin d'août 1940, Le Canada décrit de Gaulle en ces termes: «Ce brave soldat, qui incarne les plus belles traditions du génie militaire français, demeure à nos yeux un bon et valeureux Français, dont la sincérité ne peut être mise en doute et dont l'avenir justifiera la conduite. ${ }^{60}$ Dans ces conditions, les Canadiens

57 Le Canada, «De Gaulle à Dakar», 25 septembre 1940.

58 Le Soleil, "Charles de Gaulle et nous», 15 janvier 1941.

59 Le Canada, «On nous parle d'honneun», 7 mai 1942.

60 Le Canada, «L'appel du général de Gaulle au Canada français», 29 août 1940. 
français doivent appuyer de toutes leurs forces la cause incarnée par le chef de la France libre (Le Canada: 7 mentions, Le Soleil: 6). À l'occasion du premier anniversaire du ralliement de l'AEF aux gaullistes, le quotidien libéral de Québec affirme que Vichy sert très mal les intérêts de la France et que:

(...) c'est l'honneur et la liberté de leur patrie que servent héroïquement le général Charles de Gaulle et les milices de la France libre. Aussi (...) le Canada français ferait-il bien de manifester son admiration pour cet apostolat militaire pour la rédemption d'une nation qui lui reste chère entre toutes. ${ }^{61}$

Malgré ces exhortations, le message gaulliste est d'abord plutôt mal reçu par une partie importante de l'élite québécoise. Les éditorialistes font parfois allusion à ce problème dans leurs textes. En décembre 1941, Le Canada affirme que:

La méfiance de certains à l'égard de la France libre provient du fait qu'ils croient le mouvement gaulliste surtout préoccupé de chasser du pouvoir le maréchal Pétain et son gouvernement (...) et de rétablir au plus tôt dans la France libérée le régime républicain tel qu'il existait avant la guerre. Des paroles de certains politiciens de la France libre ont pu justifier dans une certaine mesure ce point de vue. ${ }^{62}$

Conscient des difficultés de la France libre au Québec, Le Canada croit qu'il serait avantageux pour ce mouvement d'établir ses quartiers généraux dans une ville française d'Amérique, Montréal ou Québec (3 mentions); ce qui ne pourrait que stimuler l'ardeur des Canadiens français pour la cause de la libération de la France. De même, soulignant qu'une grande partie des difficultés du mouvement gaulliste proviennent de son manque de légitimité, le journal souhaite que les Alliés le reconnaissent comme gouvernement français en exil (2 mentions) $)^{63}$.

À partir de 1942, le message gaulliste commence à être entendu avec plus de sympathie au Canada français. En effet, l'orientation collaborationniste de Vichy, surtout après le retour de Laval, rendent de plus en plus suspects les partisans inconditionnels de ce régime et augmentent la crédibilité des militants gaullistes. Dans un sondage Gallup dont les résultats sont publiés en août 1942, les Canadiens français répondent à la question suivante: «Lequel de ces trois

61 Le Soleil, «Le mouvement de France libre», 26 août 1941.

62 Le Canada, «La France et nous», 6 décembre 1941.

63 Le Canada, «De Gaulle au Canada», ler juin 1942, et «Des événements se préparent du côté de la France», 9 juin 1942. 
hommes accomplit le plus pour la France?»: le maréchal Pétain, 46\%; le général de Gaulle, $45 \%$; Pierre Laval, $1 \%$, et $8 \%$ sont sans opinion $^{64}$. Ayant de moins en moins l'impression de prêcher dans le désert, la presse libérale demande avec plus d'insistance aux francophones du Québec de se ranger derrière de Gaulle et cherche à marginaliser les nationalistes qui continuent de dénigrer de Gaulle et d'exalter Pétain. En juin 1942, le quotidien libéral de Montréal presse les Québécois d'en finir: «(...) avec cet esprit mauvais que le philofascisme souffle chez nous à la faveur de nos instincts de solidarité française. Notre amour et notre compassion vont à la France qui souffre, mais notre respect, notre admiration et notre gratitude vont à la France «qui combat».» ${ }^{65}$

Finalement, nous constatons que la presse libérale émet très peu de commentaires défavorables sur de Gaulle. Seul Le Canada signale que son entourage comprend des personnalités louches et, à l'été 1942, lui reproche d'avoir nommé un rallié de fraîche date à la Résistance, M. Léon Marchal, comme représentant au Canada $(2 \text { mentions })^{66}$.

La presse clérico-nationaliste est partagée au sujet du combat du général de Gaulle. Retrouvons d'abord L'Action catholique (tableau 7: $75,7 \%$ favorables, $14,9 \%$ défavorables et $9,4 \%$ neutres) qui réagit favorablement à l'action de la France libre. Comme nous l'avons vu précédemment, le journal désire avant tout éviter une querelle entre Canadiens français autour de Pétain et de Gaulle. Dans ce but, il affirme conserver une stricte neutralité et soutient qu'il n'est pas nécessaire de renier le maréchal pour admirer le chef de la France libre (18 mentions). Nous retrouvons l'idée d'une double résistance menée par deux catholiques fervents (4 mentions) qui servent héroïquement leur patrie, et dont les actions ne s'opposent pas (11 mentions). L'Action catholique défend donc de Gaulle contre les attaques des pétainistes ( 10 mentions) et condamne les gaullistes qui s'en prennent à Pétain (6 mentions). Toujours pour désamorcer des crises potentielles, le journal dément les rumeurs voulant que des personnalités catholiques québécoises, comme le juge Fabre-Surveyer, aient dénoncé le général ( 2 mentions). Louis-Philippe Roy s'adresse aux belligérants:

Cessons de voir dans les partisans de Pétain des membres de la 5ième colonne et dans les partisans de De Gaulle des impé-

64 L'Action catholique, «L'attitude des Canadiens français envers la France», 22 août $1942,3$.

65 Le Canada, «De Gaulle au Canada», 1er juin 1942.

66 Le Canada, «Représenter de Gaulle ici», 31 août 1942. 
rialistes stipendiés. Que les «généralistes» mettent une sourdine à leurs propos désobligeants et injustes à l'égard du maréchal (...). Que les «maréchalistes» fassent taire leurs ressentiments à l'égard du général, de ses partisans et de l'Angleterre. ${ }^{67}$

La majorité des mentions du général de Gaulle portent directement ou indirectement sur le débat entre pétainistes et gaullistes au Canada français. Le seul thème qui s'éloigne de cette problématique, soit la participation de la France à sa libération et à la victoire alliée, grâce à de Gaulle, n'apparaît que trois fois. La rareté des commentaires sur l'action de ce dernier tranche avec l'abondance de textes sur celle de Pétain. Ceci nous laisse croire que, malgré un discours en apparence favorable, les éditorialistes de L'Action catholique n'ont qu'un intérêt limité pour le combat du général de Gaulle, qui les passionne bien moins que la Révolution nationale du maréchal Pétain ${ }^{68}$.

La section «En marge de la guerre» reflète la même attitude: abondante couverture de Vichy et rares références à de Gaulle. Le journal exprime même des réserves quand le chef de la France libre s'oppose directement au régime de Pétain. Par exemple, lors du raid sur Dakar à la fin de septembre 1940, Louis-Philippe Roy estime que: «Le général de Gaulle a certainement manqué de clairvoyance en conduisant les Anglais à Dakar», et il en profite pour réaffirmer sa confiance dans la volonté des dirigeants de Vichy de résister aux Allemands ${ }^{69}$.

Le Devoir (tableau 8: 17,6\% favorables, 70,6\% défavorables et $11,8 \%$ neutres) accorde encore moins d'attention à de Gaulle et se distingue surtout des autres journaux par le caractère défavorable de son commentaire. Tout en reconnaissant que le chef de la France libre est un soldat courageux et un habile technicien ( 2 mentions), le quotidien nationaliste de Montréal le présente comme un entêté qui refuse d'admettre l'évidence de la défaite de son pays. De plus, compte tenu de son attitude à l'endroit du maréchal Pétain, le journal croit que seuls des gens mal intentionnés peuvent le considérer comme un grand Français.

On sent de la gêne et une certaine retenue lorsque Le Devoir doit traiter du général de Gaulle. La présence de la censure de l'information, qui pourrait sans doute difficilement tolérer que l'on dénigre

67 L'Action catholique, «L'«Action Catholique», les Alliés, la France», 20 août 1940.

68 Durant la période, le journal publie 18 éditoriaux sur la politique intérieure de Vichy, 8 sur la querelle Pétain-de Gaulle et 2 sur la France libre. Treize textes portent sur d'autres aspects de la situation de la France.

69 L'Action catholique, «En marge de la guerre européenne», 24 et 26 septembre 1940, 1. 
systématiquement un allié du Canada, semble à l'origine de ce malaise. Avec le temps cependant, les éditorialistes découvrent le seuil de tolérance de cette censure et trouvent des moyens pour la contourner. Ils se rendent ainsi rapidement compte qu'ils peuvent insister sur l'absence de légitimité des gaullistes ( 2 mentions), puisque le gouvernement canadien reconnaît toujours le régime de Vichy. Dès août 1940, Georges Pelletier aborde ce sujet en affirmant que le maréchal Pétain a été investi légalement par l'Assemblée nationale française. Il se demande qui, mieux que les députés et sénateurs français, est qualifié pour désigner le gouvernement légal de la France. Ce n'est sûrement pas: «Un simulacre de junte réunie à Londres (...). Un Comité sans autorité légale, constitué de son propre chef, sans mandat explicite défini du pays, peu importe qui l'eût appuyé hors de France. ${ }^{70}$

Ce quotidien montre également ses humeurs en se référant à des textes peu flatteurs pour de Gaulle, mais signés par des personnalités dont l'appui à la cause alliée ne fait aucun doute. En décembre 1941, Georges Pelletier insiste sur l'impopularité ( 3 mentions) et sur le peu de prestige (2 mentions) du général au sein de la population française, en faisant sienne l'opinion du chroniqueur américain John Elliot qui, dans le Herald Tribune de New York, écrit:

Le général de Gaulle n'a pas réussi à convaincre ses compatriotes qu'il est l'homme providentiel. (...) Bien des Français sympathiques à la cause que représente le général de Gaulle regrettent que ce mouvement n'ait pas un chef de plus grand prestige, de plus d'autorité. (...) Le mouvement degaulliste paraît moins fort en France, présentement, qu'en 1940 (...) il n'y a certes pas plus de $10 \%$ des Français à être partisans du général de Gaulle. ${ }^{11}$

L'impopularité du chef de la France libre s'expliquerait par le mécontentement de la population française devant ses fréquentes attaques contre les dirigeants de Vichy, principalement contre le maréchal Pétain (3 mentions). Toujours en décembre 1941, Georges Pelletier, couvrant cette fois-ci ses arrières en s'inspirant d'un texte du bulletin du Research Group de Londres, attribue l'échec des gaullistes à deux facteurs: «D'abord de Gaulle a commis un impair politique: celui de s'en prendre au maréchal Pétain, personnellement... car il est encore populaire en France. (...) Ensuite celui-ci (de Gaulle) a donné trop de temps à des attaques contre d'autres Français et trop peu d'attaques contre les Allemands.» ${ }^{72}$ Pour éviter la censure, Le Devoir

70 Le Devoir, «Le régime du maréchal Pétain», 3 août 1940.

71 Le Devoir, «La France ne trahit personne», 20 décembre 1941.

72 Loc. cit. 
n'élabore pas un discours très structuré sur de Gaulle. Il choisit le plus souvent d'ignorer les gaullistes et fait passer son message par un discours très favorable au gouvernement de Pétain, qu'il oppose à la défunte Troisième République, jugée responsable de la défaite de la France.

De même, le quotidien nationaliste de Montréal s'intéresse peu à de Gaulle dans son bloc-notes. Il se contente généralement de décrire les faits d'une façon plutôt neutre, ne se hasardant à livrer une opinion sur le général que lors d'événements importants. Au lendemain de l'échec de Dakar, il affirme que cette défaite pourrait bien signifier l'effacement prochain du chef de la France libre, dont l'autorité comme porte-parole de la France semble maintenant discréditée en Angleterre. Georges Pelletier s'explique:

De Gaulle est un très brave soldat, un technicien d'envergure, ce n'est pas un chef renseigné à fond, [comme le] fait voir le fiasco de Dakar où il a conduit l'Angleterre. L'histoire anglaise, depuis longtemps, enseigne que le gouvernement de Londres ne garde pas indéfiniment des collaborateurs étrangers qui ratent leurs entreprises, lui causant ainsi d'assez coûteuses déceptions. ${ }^{73}$

\section{CONCLUSION}

Notre analyse confirme la présence de trois discours dans la presse québécoise sur le maréchal Pétain et le général de Gaulle, durant la période où le Canada maintient ses relations diplomatiques avec le régime de Vichy ${ }^{74}$.

D'abord, nous avons la presse clérico-nationaliste qui continue de promouvoir les valeurs traditionnelles auprès de ses lecteurs. Il n'est pas surprenant qu'elle se reconnaisse dans la Révolution nationale de Pétain, qui propose le retour aux idéaux de «Travail, Famille, Patrie», en liquidant l'héritage de la Troisième République tant détestée. Passionnés par l'évolution intérieure de la France, les organes clériconationalistes s'intéressent moins au général de Gaulle, et son combat les laisse plutôt indifférents. Signalons cependant que, malgré une commune sympathie pétainiste, Le Devoir et L'Action catholique réagissent différemment à l'imbroglio français. Alors que le premier se lance dans une défense acharnée du maréchal, le second, influencé par la position de l'archevêché de Québec, adopte une attitude beau-

73 Le Devoir, «Le sort du général de Gaulle», 26 septembre 1940.

74 Ces relations sont rompues par le Canada, au début de novembre 1942, lorsque le gouvernement de Vichy ordonne à ses troupes de combattre les Alliés, débarqués en Afrique du Nord française. 
coup plus prudente. Il prétend refuser de choisir entre ces deux «grands catholiques» que sont Pétain et de Gaulle et met les Canadiens français en garde contre les conséquences de leur implication dans une querelle qui ne regarde que les Français. La présence de deux discours sur Pétain et de Gaulle dans la presse clérico-nationaliste illustre bien la diversité de ce courant, plus nuancé qu'une certaine historiographie l'a laissé entendre.

De son côté, la presse libérale, attachée aux idéaux de liberté et de démocratie, croit que seul le général de Gaulle offre l'espoir d'une libération prochaine de la France, associée à la victoire sur le nazisme. Indifférents à la Révolution nationale, les journaux libéraux fondent leurs jugements sur les dirigeants français d'abord en fonction de leur attitude sur la scène internationale. Ils accordent donc le bénéfice du doute au maréchal Pétain jusqu'à ce qu'il se compromette dans la collaboration avec l'Allemagne. Principalement à partir du printemps 1941, les quotidiens libéraux, qui cherchent avant tout à promouvoir la cause des Alliés auprès des Canadiens français, dénoncent le régime collaborateur du maréchal Pétain et incitent leurs lecteurs à reconnaître les valeurs incarnées par de Gaulle.

L'analyse du discours de la presse a ses limites et l'impact réel des opinions exprimées par les éditorialistes sur la population en général nous échappe. Une telle étude permet cependant de cerner les idées qui circulent parmi l'élite et qui, par la voie des journaux, finissent par influencer l'opinion de la masse. Elle infirme donc sérieusement la vision d'un Québec français essentiellement pétainiste pendant la Seconde Guerre mondiale. Si telle est à peu près la situation dans les mois qui suivent l'armistice de juin 1940, alors que les journaux font confiance à Pétain, les uns avec enthousiasme, les autres avec résignation, le clivage entre la presse libérale et les quotidiens clérico-nationalistes apparaît clairement dès le printemps 1941. En fait, on peut même parler de trois discours différents, tant les positions du Devoir sur la situation de la France s'écartent de celles de L'Action catholique. S'ajoutant aux plus récents travaux en histoire du Québec contemporain, notre étude peut certainement contribuer à l'élaboration d'un portrait plus équilibré et plus juste de la société québécoise de la première moitié du $\mathrm{XX}^{\mathrm{e}}$ siècle. En mettant en lumière l'adhésion à d'autres valeurs idéologiques d'une partie significative de l'élite francophone d'avant 1945, elle remet en question cette vision, encore souvent acceptée inconditionnellement, d'une société québécoise arriérée, repliée sur elle-même et caractérisée par son monolithisme idéologique.

Après le 11 novembre 1942, moment de l'invasion de la zone libre par l'Allemagne, le débat autour de Pétain et de Gaulle perd de son 
acuité au Québec, tant le régime de Vichy est alors discrédité dans l'opinion. Cette accalmie n'est toutefois que temporaire puisque la controverse rebondit après la guerre. Les milieux clérico-nationalistes se portent alors à la défense de Pétain, condamné à mort par la France libérée, tandis que la presse libérale défend la politique d'épuration pratiquée par le gouvernement du général de Gaulle ${ }^{75}$. Les Québécois et la vie politique française, 1914-1969: parentés et dissemblances. Thèse de Ph.D., Centre d'études canadiennes de Bordeaux, 1975, 128-145. 


\title{
TABLEAU 1
}

La perception du maréchal Pétain dans la presse québécoise: analyse de contenu des éditoriaux sur la France parus entre juin 1940 et novembre 1942

\author{
Mot-clef: Pétain Journal: Le Devoir Apparitions: 86
}

\begin{tabular}{lc}
\hline Thèmes favorables Nombre: 78 Pourcentage: $\mathbf{9 0 , 7 \%}$ & Fréquence \\
\hline Pétain résiste à l'Allemagne et refuse de collaborer avec elle & 15 \\
Pétain travaille à la restauration de la France, appréciation de ses réformes & 11 \\
Les gaullistes, les Anglo-saxons, etc., qui s'attaquent à Pétain sont des gens de & 10 \\
mauvaise foi & 8 \\
L'intégrité de Pétain ne fait pas de doute, il faut le respecter & 7 \\
Les Français appuient Pétain et lui font confiance & 5 \\
Pétain s'est sacrifié pour sauver la France au moment de l'armistice & 4 \\
Pétain respecte scrupuleusement les termes de l'armistice & 3 \\
Pétain est le chef légitime de la France & 3 \\
Pétain s'entend bien avec les États-Unis et a confiance en Roosevelt & 3 \\
Pétain est réellement le maître à Vichy et assume ses décisions & 2 \\
en toute lucidité & 2 \\
La flotte et l'empire sont des atouts importants pour Pétain & \\
Pétain, c'est Vichy &
\end{tabular}

Thèmes défavorables Nombre: 5 Pourcentage: 5,8\% Fréquence

Il y a des gens louches dans l'entourage de Pétain Pétain n'est pas libre. Il est impuissant devant l'Allemagne Une reconnaissance de la France libre jetterait Pétain dans les bras de l'Allemagne 1

3 mentions sont neutres.

\section{Annexe: Répartition dans le temps des mentions positives et négatives}

$$
\text { 16-06-40 au 30-04-41 1-05-41 au 17-04-42 18-04-42 au 10-11-42 }
$$

$\begin{array}{lrrr}\text { Favorables } & 58 & 20 & 0 \\ \text { Défavorables } & 4 & 1 & 0\end{array}$

NOTE: Les tableaux 1 à 8 n'incluent que les thèmes pertinents au sujet traité et, sauf dans les cas où il y a réel déséquilibre entre les mentions favorables et défavorables, que ceux revenant au moins deux fois dans les éditoriaux 
TABLEAU 2

La perception du maréchal Pétain dans la presse québécoise: analyse de contenu des éditoriaux portant sur la France parus entre juin 1940 et novembre 1942

Mot-clef: Pétain Journal: L'Action catholique Apparitions: 225

Thèmes favorables Nombre:155 Pourcentage: 68,9\% $\quad$ Fréquence

Pétain travaille à la restauration de la France, appéciation de ses réformes $\quad 37$

Les gaullistes, les Anglophones, etc., ont tort d'attaquer Pétain 13

Il n'est pas nécessaire de renier de Gaulle pour admirer Pétain.

Les Canadiens français peuvent admirer les deux chefs 11

Comme de Gaulle, Pétain sert héroïquement la France.

Leur action ne s'oppose pas 11

Pétain résiste à l'Allemagne et refuse de collaborer avec elle 11

$\begin{array}{ll}\text { Pétain gouverne bien la France et agit dans le sens des intérêts de sa patrie } & 10\end{array}$

Il faut faire confiance à Pétain même si l'on est pas d'accord avec les politiques de Vichy (idée d'indulgence) 9

Pétain n'a pas trahi sa patrie en acceptant l'armistice 9

Pétain s'est sacrifié pour sauver la France au moment de l'armistice $\quad 8$

Pétain a bien fait de renvoyer Laval. Il ne doit pas le reprendre

dans son gouvernement

Pétain est un catholique fervent

Les États-Unis aident Pétain et lui font confiance

Pétain est bien différent de Hitler et de Laval 3

S'il était libre, Pétain n'agirait pas comme il le fait 3

Pétain a aboli la Troisième République, responsable de la défaite 2

Pétain est réellement le maître à Vichy. Il n'est pas un fantoche 2

Thèmes défavorables Nombre: 61 Pourcentage: $27,1 \% \quad$ Fréquence

$\begin{array}{lr}\text { Pétain a commis une erreur en acceptant l'armistice } & 15\end{array}$

Les partisans de Pétain ont tort de s'attaquer à de Gaulle $\quad 8$

Pétain fait trop confiance à Laval. Laval complote contre lui 7

$\begin{array}{ll}\text { Pétain peut commettre des erreurs, même s'il est catholique } & 6\end{array}$

Pétain n'est pas libre. Il est impuissant devant l'Allemagne 4

Son grand âge empêche Pétain de résister 3

Pétain collabore avec l'Allemagne 2

Critique des politiques de Pétain (autres que la collaboration) 2

Les nazis travaillent à miner le prestige de Pétain 2

9 mentions sont neutres.

Annexe: Répartition dans le temps des mentions positives et négatives

16-06-40 au 30-04-41 1-05-41 au 17-04-42 18-04-42 au 10-11-42

$\begin{array}{llll}\text { Favorables } & 140 & 10 & 5\end{array}$

$\begin{array}{llll}\text { Défavorables } & 52 & 8 & 1\end{array}$ 


\section{TABLEAU 3}

La perception du maréchal Pétain dans la presse québécoise: analyse de contenu des éditoriaux portant sur la France parus entre juin 1940 et novembre 1942

Mot-clef: Pétain Journal: Le Canada Apparitions: 173

\begin{tabular}{lc}
\hline Thèmes favorables Nombre: 70 Pourcentage: $\mathbf{4 0 , 5 \%}$ & Fréquence \\
\hline $\begin{array}{l}\text { Pétain gouverne bien la France et agit en fonction des intérêts de sa patrie } \\
\text { Pétain s'oppose aux politiques de Laval }\end{array}$ & 10 \\
Pétain a bien fait de renvoyer Laval. Il ne doit pas le reprendre & 7 \\
dans son gouvernement & 7 \\
L'intégrité de Pétain ne fait pas de doute. Il est honnête et sincère & 6 \\
Pétain jouit d'une réelle autonomie à Vichy. Il n'est pas un fantoche & 6 \\
Pétain résiste à l'Allemagne et refuse de collaborer avec elle & 5 \\
Certaines des réformes mises de l'avant par Pétain dans le cadre & 3 \\
de la Révolution nationale sont excellentes & 3 \\
S'il était libre, Pétain n'agirait pas comme il le fait & 3 \\
Pétain tente de donner une forme de représentation populaire à son régime & 3 \\
Pétain reste l'ami de l'Angleterre & 3 \\
Pétain se devait de capituler en juin 1940 & 2 \\
On doit faire confiance à Pétain même si l'on n'est pas d'accord & 2 \\
avec les politiques de Vichy & 2 \\
Pétain sait que son régime est transitoire & 2 \\
Les Canadiens français peuvent faire confiance à la fois à Pétain et à de Gaulle & 2
\end{tabular}

\begin{tabular}{llll}
\hline Thèmes défavorables Nombre: 79 & Pourcentage: $45,7 \%$ & Fréquence \\
\hline
\end{tabular}

Pétain n'est pas libre. Il est impuissant devant l'Allemagne 21

Pétain est manipulé par Laval. Laval complote contre lui 16

$\begin{array}{lr}\text { Pétain collabore avec l'Allemagne } & 6\end{array}$

Critique des politiques de Pétain (autres que la collaboration) 6

Au Canada français, des philofascistes exaltent la personne du maréchal Pétain 5

Pétain travaille contre l'intérêt de la France 4

Pétain a commis une erreur en acceptant l'armistice 4

Pétain n'a plus le droit de parler de l'honneur de la France 3

Pétain est hostile à l'Angleterre 3

L'opposition Pétain-de Gaulle a de graves répercussions au Canada français 2

\section{4 mentions sont neutres.}

Annexe: Répartition dans le temps des mentions positives et négatives

16-06-40 au 30-04-41 1-05-42 au 17-04-42 18-04-42 au 10-11-42

$\begin{array}{llll}\text { Favorables } & 42 & 24 & 4\end{array}$

$\begin{array}{llll}\text { Défavorables } & 8 & 28 & 43\end{array}$ 


\section{TABLEAU 4}

La perception du maréchal Pétain dans la presse québécoise: analyse de contenu des éditoriaux portant sur la France parus entre juin 1940 et novembre 1942

Mot-clef: Pétain Journal: Le Soleil Apparitions: 203

\begin{tabular}{llll}
\hline Thèmes favorables & Nombre: 77 & Pourcentage: $37,9 \%$ & Fréquence \\
\hline
\end{tabular}

On doit faire confiance à Pétain même si l'on n'est pas d'accord avec

les politiques de Vichy (idée d'indulgence) 13

Pétain résiste à l'Allemagne et refuse de collaborer avec elle 9

Pétain veut éviter le maximum de souffrances aux Français 7

Pétain gouverne bien la France et agit dans le sens des intérêts de sa patrie $\quad 7$

$\begin{array}{ll}\text { Weygand appuie Pétain } & 6\end{array}$

Pétain jouit d'une réelle autonomie à Vichy. Il n'est pas un fantoche 5

S'il était libre, Pétain n'agirait pas comme il le fait 5

L'intégrité de Pétain ne fait pas de doute. Il est honnête et sincère 4

Pétain approuve de Gaulle dans le fond de son coeur 4

Pétain a eu une influence bénéfique au moment de la défaite 4

Pétain a bien fait de renvoyer Laval. Il ne doit pas le reprendre
dans son gouvernement

Pétain est le chef légitime de la France 3

Pétain est un catholique fervent 3

De Gaulle se refuse à condamner Pétain $\quad 2$

\begin{tabular}{llll}
\hline Thèmes défavorables & Nombre: 112 & Pourcentage: $55,2 \%$ & Fréquence \\
\hline
\end{tabular}

Pétain n'est pas libre. Il est impuisant devant l'Allemagne 19

Pétain a commis une erreur en acceptant l'armistice 14

$\begin{array}{ll}\text { Pétain collabore avec l'Allemagne } & 11\end{array}$

Pétain est un vieil entêté dont la carrière est placée sous le signe du défaitisme $\quad 10$

$\begin{array}{ll}\text { Pétain est sympathique au fascisme et à la dictature } & 9\end{array}$

Pétain travaille contre l'intéret de la France 7

Une partie importante de la population française ne reconnaît pas l'autorité de Pétain 6

La Révolution nationale de Pétain s'inspire du fascisme 5

Pétain n'a pas su bien choisir les membres de son gouvemement 4

Pétain est hostile à l'Angleterre 4

Pétain a une peur exagérée du communisme 4

Les politiques de Pétain font souffrir les Français 4

Pétain trompe les Alliés sur ses intentions 4

Pétain n'incarne pas la France $\quad 3$

Pétain persécute les Juifs 2

Pétain est vieux 2

14 mentions sont neutres.

Annexe: Répartition dans le temps des mentions positives et négatives

16-06-40 au 30-04-41 1-05-41 au 17-04-42 18-04-42 au 10-11-42

$\begin{array}{llll}\text { Favorables } & 56 & 21 & 0\end{array}$

$\begin{array}{llll}\text { Défavorables } & 40 & 67 & 5\end{array}$ 


\section{TABLEAU 5}

La perception du général de Gaulle dans la presse québécoise: analyse de contenu des éditoriaux portant sur la France parus entre juin 1940 et novembre 1942

Mot-clef: de Gaulle Journal: Le Canada Apparitions: 71

\begin{tabular}{llll}
\hline Thèmes favorables & Nombre: 59 & Pourcentage: $83,1 \%$ & Fréquence
\end{tabular}

De Gaulle combat pour libérer la France

8

De Gaulle est peiné de devoir se battre contre d'autres Français

De Gaulle est un patriote, à l'attitude pure et honorable, dont l'action va dans

le sens des intérêts et de la grandeur de sa patrie

De Gaulle poursuit la lutte aux côtés de l'Angleterre

Les Canadiens français doivent appuyer de Gaulle

De Gaulle reçoit l'appui de la population française

De Gaulle sert mieux l'honneur de sa patrie que Pétain.

Son action s'oppose à celle de Vichy

De Gaulle devrait établir son quartier général au Québec

Les Alliés doivent reconnaître le mouvement du général de Gaulle comme gouvernement français en exil

es Canadiens français peuvent faire confiance à la fois à Pétain et à de Gaulle

\begin{tabular}{llll}
\hline Thèmes défavorables Nombre: 4 & Pourcentage: 5,6\% & Fréquence \\
\hline
\end{tabular}

De Gaulle ne doit pas nommer un rallié de fraiche date à la Résistance comme représentant au Canada

Le mouvement du général de Gaulle comprend des personnalités douteuses

8 mentions sont neutres.

Annexe: Répartition dans le temps des mentions positives et négatives

$$
\text { 16-06-40 au 30-04-41 1-05-41 au 17-04-42 18-04-42 au 10-11-42 }
$$

Favorables

19

14 
TABLEAU 6

La perception du général de Gaulle dans la presse québécoise: analyse de contenu des éditoriaux portant sur la France parus entre juin 1940 et novembre 1942

Mot-clef: de Gaulle Journal: Le Soleil Apparitions: 80

$\begin{array}{llll}\text { Thèmes favorables Nombre: } 66 & \text { Pourcentage: } 82,5 \% & \text { Fréquence }\end{array}$

De Gaulle poursuit la lutte aux côtés de l'Angleterre 10

De Gaulle est un patriote, à l'attitude pure et honorable, dont l'action va dans le sens des intérêts et de la grandeur de sa patrie

De Gaulle combat pour libérer la France

De Gaulle reçoit l'appui de la population française

L'armée française et l'empire colonial français rejoignent de Gaulle

L'attitude de de Gaulle est meilleure que celle des dirigeants de Vichy

Les Canadiens français doivent appuyer de Gaulle

Pétain appuie de Gaulle dans le fond de son coeur. Il a déja fait son éloge 5

De Gaulle se refuse à condamner Pétain

Les Alliés ont tort d'adopter une attitude négative à l'endroit de de Gaulle

Thèmes défavorables Nombre: 0 Pourcentage: $0 \%$

14 mentions sont inclassables.

Annexe: Répartition dans le temps des mentions positives et négatives

16-06-40 au 30-04-41 1-05-41 au 17-04-42 18-04-42 au 10-11-42

Favorables

43

12

Défavorables

0

0

0 


\section{TABLEAU 7}

La perception du général de Gaulle dans la presse québécoise: analyse de contenu des éditoriaux portant sur la France parus entre juin 1940 et novembre 1942

Mot-clef: de Gaulle Journal: L'Action catholique Apparitions: 74

\begin{tabular}{llll}
\hline Thèmes favorables & Nombre: 56 & Pourcentage: $\mathbf{7 5 , 7 \%}$ & Fréquence \\
\hline
\end{tabular}

Il n'est pas nécessaire pour les Canadiens français de renier Pétain pour admirer de Gaulle

Comme Pétain, de Gaulle sert hérö̈quement sa patrie. Leurs actions ne s'opposent pas

Les partisans de Pétain ont tort de s'attaquer à de Gaulle

Comme Pétain, de Gaulle est un catholique convaincu

Les Canadiens français appuient et admirent de Gaulle

Grâce à de Gaulle, la France participe à la victoire alliée

De Gaulle avait prévu la défaite de la France

Il est faux que des personnalités catholiques du Québec se soient attaquées à de Gaulle

Thèmes défavorables Nombre: $11 \quad$ Pourcentage: $14,9 \% \quad$ Fréquence

Les partisans de de Gaulle ont tort de s'attaquer à Pétain

De Gaulle peut commettre des erreurs

Pétain a un rôle plus ingrat que de Gaulle

De Gaulle devra éviter certains sujets délicats lorsqu'il viendra au Canada

7 mentions sont neutres.

Annexe: Répartition dans le temps des mentions positives et négatives 16-06-40 au 30-04-41 1-05-41 au 17-04-42 18-04-42 au 10-11-42

\begin{tabular}{llll} 
Favorables & 52 & 4 & 0 \\
Défavorables & 11 & 0 & 0 \\
\hline
\end{tabular}




\section{TABLEAU 8}

La perception du général de Gaulle dans la presse québécoise: analyse de contenu des éditoriaux portant sur la France parus entre juin 1940 et novembre 1942

Mot-clef: de Gaulle Journal: Le Devoir Apparitions: 17

\begin{tabular}{llll}
\hline Thèmes favorables & Nombre: 3 & Pourcentage: $17,6 \%$ & Fréquence
\end{tabular}

De Gaulle est un soldat courageux et un habile technicien 2

De Gaulle sera peut-être le libérateur de la France 1

\begin{tabular}{llll}
\hline Thèmes défavorables & Nombre: 12 & Pourcentage: $70,6 \%$ & Fréquence \\
\hline
\end{tabular}

Les Français n'appuient pas de Gaulle 3

De Gaulle a tort de s'attaquer au maréchal Pétain 3

De Gaulle n'a aucune légitimité 2

De Gaulle n'a pas de prestige 2

De Gaulle s'obstine même si la guerre est perdue pour son pays 1

Les partisans de de Gaulle sont des gens mal intentionnés 1

2 mentions sont neutres.

Annexe: Répartition dans le temps des mentions positives et négatives

16-06-40 au 30-04-41 1-05-41 au 17-04-42 18-04-42 au 10-11-42

$\begin{array}{llll}\text { Favorables } & 3 & 0 & 0\end{array}$

Défavorables $\quad 2 \quad 10 \quad 0$ 